\title{
Seamen's dispensary, Liverpool 1924-1991
}

O P Arya, J B Plumb

\section{Introduction}

The city of Liverpool is famous for many things. One of them which achieved renown on every continent was Dr Ross's Clinic, a name bestowed by seamen of every nationality upon the building erected by Liverpool Corporation in 1923, and described on the bronze plaque beside its front door as "THE SEAMEN'S DISPENSARY. OPEN TO SEAMEN OF ALL NATIONS FOR FREE TREATMENT AND ADVICE".

The Seamen's Dispensary has been in the forefront, actively participating in the events spanning almost seven decades, comprising evolution and significant changes in the practice of the specialty now called Genitourinary Medicine (GUM).

After 67 years of the most valuable service, the Seamen's Dispensary closed in December 1991. A brief history of its origin and the placing on record of its contribution to sexually transmitted disease control in Liverpool and beyond would be a fitting epitaph.

\section{Background}

1. Before 20th century

Liverpool was a small fishing village until 1207 when King John's Charter conferred upon it a borough status. ${ }^{1}$ It steadily grew in size and importance, owing largely to the West Indian trade and slave trade with W. Africa and the Americas. By the beginning of the 17th century, the Liverpool port was busy importing and exporting goods.

By the end of the 18th century the city was very rich, mostly as a result of shipping. The city continued to flourish well into the 20th century, its port serving as the terminus for ships to and from every region of the world bringing in cargos and seafarers of all nationalities. Liverpool had become the gateway of the British Empire. ${ }^{2}$

Liverpool's sailortown had sprawled over a large area around Paradise Street and Canning Place. It was around here that the famous Liverpool "forebitter", Maggie May, and others plied their trade. The sailors had to run the gauntlet to pass the parading prostitutes.

"When I steered into her, I hadn't got a care, She waz cruisin' up an' down ol' Canning Place,

She waz dressed in a gown so fine, like a frigate of the line,

An I bein' a sailorman gave chase", ${ }^{3}$

The special needs of the seafarers had been recognized; for example The General Infirmary in Liverpool, which opened in 1749, had two wings for the maintenance of "decayed seamen, their wives and children". ${ }^{4}$ However, patients with venereal disease (VD) in general, were treated as outcasts. To secure the "decency and good order of the house, venereal patients were to be so entirely detached as not to have the least intercourse with the other parts of the hospital". 4 Nevertheless, some arrangements had existed at the Royal Infirmary, the Northern Hospital, the Stanley Hospital and the Royal Southern Hospital (opened respectively in 1824, 1834, 1867 and 1872) for the gratuitous treatment of venereal disease. ${ }^{4}$

\section{Royal Commission}

The growing recognition of the ravages of venereal diseases in the United Kingdom in the earlier part of this century led to the setting up of a Royal Commission in 1913. It was required to investigate the prevalence of venereal diseases in Great Britain, and to recommend methods for their alleviation and prevention. Its report published in $1916^{5}$ revealed high mortality and morbidity from late syphilis and gonorrhoea eg $10 \%$ of the London working class infected with syphilis, and $25 \%$ of the infantile blindness attributed to gonococcal ophthalmia. ${ }^{6}$

Liverpool was no exception; for example 515 cases of ophthalmia neonatorum (mainly gonococcal) were notified during the year 1916 (population of the city 777,247$),{ }^{7}$ and $15 \%$ of the still-births were considered to be due to syphilis. ${ }^{8}$

The Venereal Diseases Act 1917 was a watershed for venereal disease control in the United Kingdom. It defined venereal diseases as syphilis, gonorrhoea and chancroid. The treatment by quacks was prohibited and the clinics, many of them new, came under the control of specialists in venereal diseases.

\section{Liverpool Response}

The Venereal Disease Regulations of 1916 required each . County or County Borough Council to provide free and confidential treatment for venereal diseases in its area, and at convenient times. Accordingly, in Liverpool, a Venereal Disease Scheme was established in 1917 under the Regulations of the Local Government Board in accordance with the recommendations of the Royal Commission, that is, to provide free and expert diagnostic and treatment facilities to sufferers of VD, and to disseminate information on the dangers of VD and on facilities for free treatment. Consequently, clinics were set up in every leading hospital of the city, initially, in 1917, at the 
Royal Infirmary, Royal Southern Hospital, Skin Hospital and the Cancer and Skin Hospital and a year later, at the Stanley Hospital and David Lewis Northern Hospital. Daily irrigation facilities to treat gonorrhoea were available and fully utilised at all the clinics.

In addition, by arrangement with the Diocesan Association, a Medical Home was established at 283 Edge Lane for the treatment of young girls found to be suffering from VD. These girls were unmarried, their ages ranging from 14-23 and they were mostly first offenders. They were referred from other VD clinics in the town, from Salvation Army Homes, from Homes for unmarried mothers, Rescue Homes, prisons and other institutions. The moral climate of the time can be gauged by the Medical Officer's assurance of the desire "to give the best treatment under moral influences in the hope of reclaiming some of these patients". 9 Thus, a prostitute was only admitted under exceptional circumstances.

The educational work included lectures to the public, seamen, workmen at industrial concerns, various clubs frequented by boys and girls, scout associations, the clergy and others.

While Parliament was debating the 1917 Act, the Liverpool Corporation Health Committee was busy suggesting a number of measures of its own. These were presented to the Ministry of Health but were opposed in the House of Commons. They ranged from powers to exercise compulsion over certain types of patients to making parents or guardians responsible for the completion of treatment of patients under the age of 16 years. ${ }^{9}$

\section{Origin of seamen's dispensary}

The Liverpool Royal Infirmary Clinic was having the largest number of patients on its books. A significant proportion ( $40 \%$ in 1920$)$ of those whose occupation was known were seafarers. This problem posed by large numbers of seafarers needed to be addressed and was not helped by the Merchant Shipping Act of 1906 which while providing for the medical treatment of the sick sailor, retained "the proviso that a seaman suffering from venereal disease shall be excluded from such benefits". ${ }^{10}$

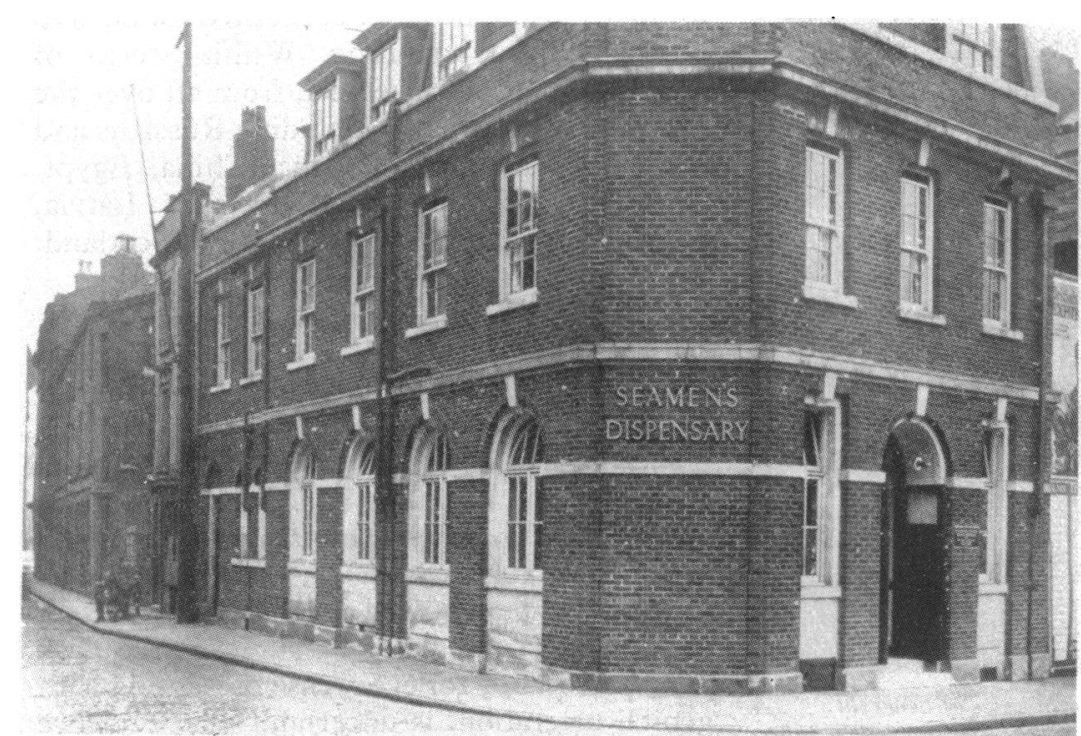

Figure 1 Seamen's Dispensary.
Earlier, Liverpool Corporation had recognized the special need of health care facilities, including those for venereal disease, for seamen of all nationalities. ${ }^{9}$ The premises were to be designated as the Seamen's Dispensary. The latter was not to be labelled as an institution specially for venereal diseases because that would prejudice not only the prospects of obtaining a site, "but also the usefulness of the premises even in regard to venereal diseases". ${ }^{11}$ A suitable site for a Seamen's Dispensary was eventually found. After obtaining the approval of the Ministry of Health, the tender of Messrs R. Wearing \& Sons was accepted and the building was completed in 1923 at a cost of $£ 4,649$. The Dispensary was opened by the Lord Mayor of Liverpool on 28th January 1924. ${ }^{12}$

The site chosen was in the neighbourhood of the Sailor's Home and other centres where sailors and others connected with seafaring life usually congregated. It was intended primarily to deal with venereal disease. However, other ailments including tropical diseases were also to be taken care of and if necessary, such patients were to be referred to other suitable institutions. The medical officer in charge also acted in an advisory capacity to medical officers of ships, ships' captains and foreign consulates.

\section{Brussels Agreement}

In November 1924, the Ministry of Health issued a memorandum intimating that arrangements concerning treatment of venereal diseases in seamen had been agreed at an International Convention (Brussels Agreement). The countries which ratified this Agreement were to establish clinics for diagnosis and treatment of venereal diseases, in all principal sea and river ports, free of charge, to all merchant seamen and watermen. By now, of course, in Liverpool, a number of treatment centres, including the Seamen's Dispensary, with the appropriate facilities were already in place.

\section{Seamen's Dispensary activities and progress} (1924-1938)

In the earlier years the Seamen's Dispensary was open from 9.30 am to $8.00 \mathrm{pm}$, and the staff consisted of one whole-time Assistant Medical Officer and two orderlies. While one orderly attended on the Medical Officer during the examination and treatment of patients, the other supervised the routine irrigation treatment of cases of gonorrhoea. The latter orderly resided on the premises in the flat on the second floor beneath a quaint mansard roof. Figures 1, 2,3 and 4 indicate the appearance of the building and general views and equipment of the consulting and operating rooms and irrigation cubicles.

Dr A O F Ross (1893-1954)

In 1924 Dr Andrew O F Ross became Physician in Charge of the Seamen's Dispensary. He was a powerful character of whom anecdotes abound and whose reputation grew with the telling.

The dispensary was adjacent to a public 


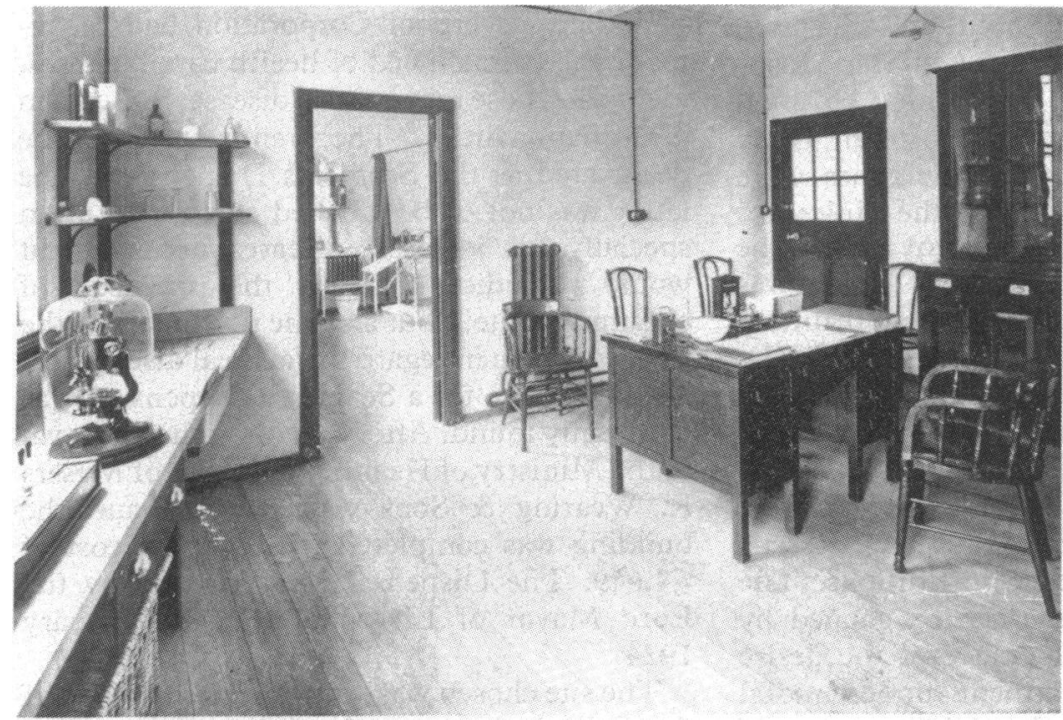

Figure 2 Medical Officers' consulting room, with facilities for bacteriological and microscopical investigations.

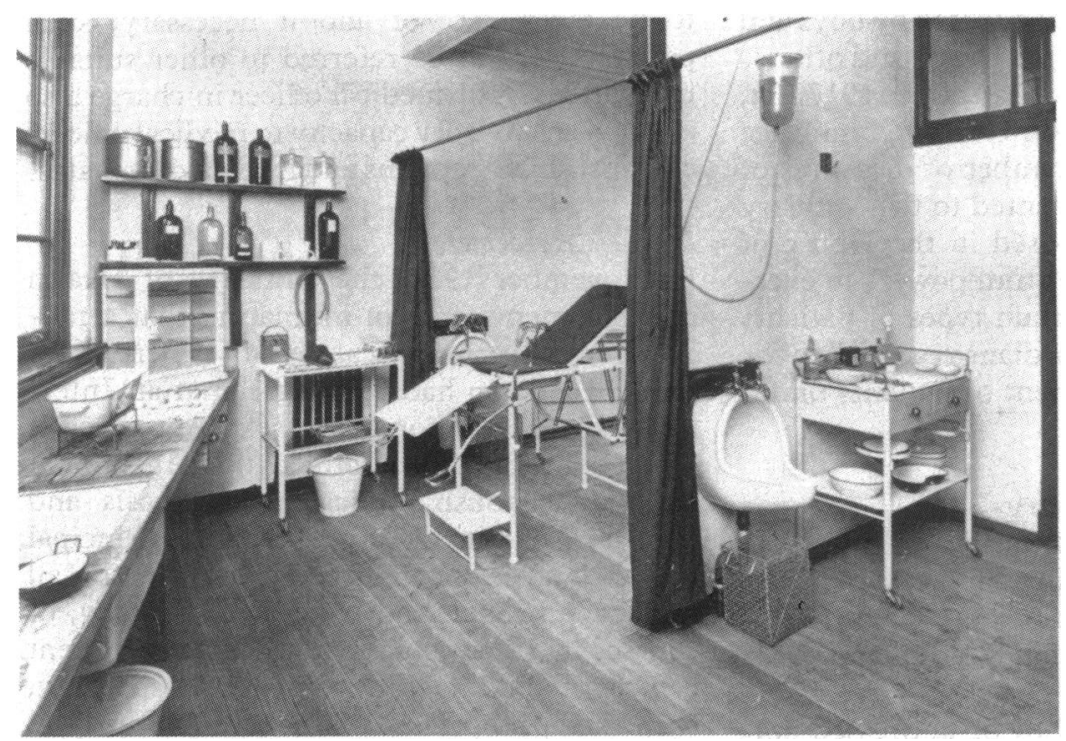

Figure 3 Operating room, with modern conveniences for examination and treatment.

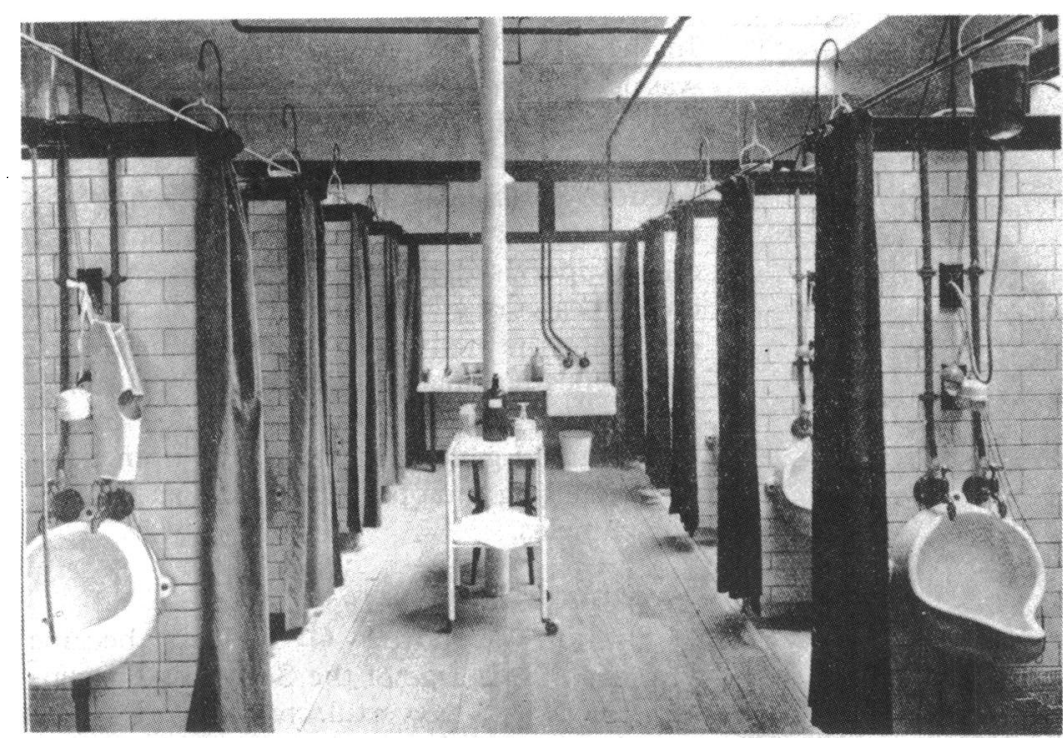

Figure 4 Curtained cubicles of irrigation and other treatment of cases of venereal disease. The patients entered from flanking corridors and the central corridor was for the medical officer and attendants. house and public urinal, a juxtaposition that came to be known irreverently as Ross's Triad. So exasperated did he become with patients attending who had emptied their bladder immediately before arrival, that he used his influence with the Public Health Committee to get the offending convenience demolished.

He was also full of humour, sensitivity and had an academic approach. The venereal disease problem among the seafarers was one of his main preoccupations. In view of their special circumstances, he developed, in 1924, an intensive treatment scheme, comprising arsenicals and bismuth injections, for early syphilis, which was soon adapted by many other centres dealing with seafarers. Dr Ross, along with his colleagues, also conducted the early field trials of penicillin in the treatment of syphilis. ${ }^{13}$

The doubling of attendances within four years of the Seamen's Dispensary opening was largely attributed to the interest, attention and personality of Dr Ross.

\section{Workload}

The value of the Seamen's Dispensary was quickly demonstrated by a marked increase in the new and total attendances (table 1). Standard practice of the time would undoubtedly have contributed to the latter. For as soon as gonorrhoea was diagnosed, a regimen of urethral irrigations for 28 days was instituted. Irrigations averaged about 100 per diem. ${ }^{14} \mathrm{~A}$ course of treatment for syphilis with arsenicals and bismuth injections would last for even longer, namely six weeks, and was to be repeated on two further occasions for those with early infections.

The convenience and attraction of the Seamen's Dispensary to the seafarers were further reflected in the coincident decline (less than $15 \%$ in 1926 compared with $40 \%$ in 1921 ) in the number of seafaring people attending the Liverpool Royal Infirmary.

There were also non-seafarers, mainly local Merseysiders, attending the Seamen's Dispensary. It was indeed intended that the dispensary would serve the general population as well as the seamen, although right from the start and for many years the latter accounted for $80 \%$ to $90 \%$ of those attending. Within weeks of opening, there were seamen from all over the world being registered including Russians and seamen from Africa, Burma, China, Egypt, Germany, Greece, India, Ireland, Latvia, Malta, the Netherlands, Norway, Scotland, Spain, Sweden and Wales.

The statistics up to 1950 comprised only four categories, namely, syphilis, soft chancre (that is, chancroid), gonorrhoea and non-venereal cases. The diagnostic tests used included dark field examination for spirochaetes, Wasserman Reaction for syphilis, and urethral smears stained with methylene blue, and occasionally cultures for gonorrhoea.

Whether the required appropriate tests were performed on all patients, for example dark field microscopy for every case presenting with genital ulceration, is uncertain. The evidence available (albeit indirect such as the recorded 
Table 1 Seaman's Dispensary attendances

\begin{tabular}{llllcll}
\hline Year & New Cases & $\begin{array}{l}\text { Early } \\
\text { Syphilis }\end{array}$ & Chancroid & Gonorrhoea & NGU & $\begin{array}{l}\text { Total } \\
\text { Attendances }\end{array}$ \\
\hline 1924 & 565 & 102 & 50 & 302 & NA & 8,322 \\
1925 & 1084 & 180 & 148 & 636 & NA & 27,265 \\
1930 & 2262 & 240 & 141 & 1113 & NA & 60,067 \\
1935 & 2259 & 230 & 131 & 968 & NA & 52,804 \\
1940 & 2884 & 190 & 173 & 1281 & NA & 27,369 \\
1945 & 5307 & NA & NA & NA & NA & 35,075 \\
1946 & NA & 436 & NA & 2278 & NA & NA \\
1950 & 4503 & 105 & NA & 856 & NA & 18,102 \\
$1955 / 56^{\star}$ & 4146 & 54 & 34 & 651 & NA & 11,893 \\
$1960 / 61^{\star}$ & 4376 & 52 & 28 & 783 & 700 & 14,053 \\
$1965 / 66^{\star}$ & 4283 & 91 & NA & 764 & NA & 11,406 \\
1970 & 4297 & 26 & 2 & 1161 & 887 & 11,200 \\
1975 & 3792 & 33 & 1 & 685 & 1108 & 9,900 \\
1980 & 3795 & 22 & - & 413 & 1186 & 9,500 \\
1985 & 4221 & 12 & - & 412 & 1081 & 11,001 \\
1987 & 3267 & 3 & 1 & 181 & 890 & 8,505 \\
1988 & 2571 & - & 2 & 87 & 712 & 6,770 \\
1989 & 2457 & - & 5 & 77 & 596 & 6,050 \\
1990 & 2097 & - & 1 & 51 & 517 & 6,183 \\
\hline
\end{tabular}

*-fiscal year, April to March NA-not available.

numbers of examinations of pathological material) shows this was not the case. The heavy workload would certainly have precluded that, since the medical officer is reported to have seen 80 patients in a day. ${ }^{14}$

Nevertheless, with regard to syphilis, efforts were made to stage the disease, and this would have necessitated elaborate examination and testing. In 1928, $25 \%$ of the syphilis cases presented with primary sore but were seronegative; $24 \%$ of the cases presented with primary sore and positive Wasserman test, $8 \%$ were in secondary stage and the remainder comprised late or latent stage including treated cases of more than 2 years' duration. ${ }^{15}$

The ratio of syphilis to gonorrhoea corresponded to that for the country generally (being 1:2 in the earlier years to $1: 8$ in later years). Epididymitis following gonococcal infection was frequently encountered among men whose voyages from far off ports lasted several weeks.

Chancroid was seen much more frequently in the Seamen's Dispensary than in any of the other city clinics. That was because the seafarers mainly patronised the Seamen's Dispensary. ${ }^{16}$

Of the venereal infections diagnosed at the Seamen's Dispensary in 1929, gonorrhoea accounted for $61 \%$, syphilis $29 \%$ and chancroid $10 \%{ }^{16}$

Within four years of opening, the attendances at the Seamen's Dispensary accounted for over half of the aggregate of attendances for all "VD" clinics in Liverpool.

The number of patients who ceased to attend before cure was completed remained consistently high. This was not at all surprising in view of the rather prolonged and irksome treatment. It was, however, noted that a close personal touch with the patient and interest in his case helped to motivate the sufferer to continue treatment.

Obviously, the more difficult cases to handle were the seafarers who were not willing to give up their posts for the long duration required to complete a course of treatment. In these cases the methods employed to assist in the continuation of treatment included: (1) issuing travel documents (V15a and later V44 for inter- national travel) where the essential particulars of the patient's case and treatment were entered and thus treatment could continue by any medical officer with appropriate facilities. (2) a letter to the ship's surgeon who was welcome, and indeed invited, to visit the Dispensary, and have the patient's treatment explained so as to carry on the treatment at sea.

\section{Source of infection and contact tracing}

Based on the history of sources of infection obtained by Dr Ross from 3500 consecutive cases of venereal disease, prostitutes were responsible for the infection of $3015(86 \%)$. Of the latter, $37 \%$ had acquired the infection in Great Britain, 20\% in other European countries and $20 \%$ in South America and West Africa ${ }^{15}$ Lack of prophylactic measures rather than excessive alcohol was the main contributory factor.

Attempts were always made to trace and bring the contacts under observation and treatment.

\section{Sulphonamide era}

In 1938, for the first time, there was a significant reduction in the number of total attendances (37024 and 55131 in 1938 and 1937 respectively). This decrease in attendances of $32 \%$ was accomplished as a result of the sulphonamide group of drugs, especially " $M$ \& B 693" which had become and remained a household name for many years in many parts of the world. This had proved efficacious in the treatment of gonorrhoea, chancroid, lymphogranuloma venereum, granuloma inguinale, but not syphilis. The treatment regimen for gonorrhoea had to be completely revised. The duration of treatment was reduced considerably and tests for cure called for more liberal use of culture methods.

\section{World war II (1 Sept 1939 to 2 Sept 1945)}

There was a dramatic increase in the number of new cases, especially of gonorrhoea and early syphilis in 1941 compared with 1940 (gonorrhoea 1281 cases in 1940 and 1604 in 1941, syphilis 190 cases in 1940 and 302 in 1941). (See also table 1). This almost certainly reflected the effects of the second World War. The figures for 1942 to 1945 are not available, but those for 1946, that is, the year following the end of the war, were higher than in any year recorded in the Seamen's Dispensary (table 1).

The Seamen's Dispensary is a Grade 2 listed building. Although the surrounding area was relentlessly bombed by the Germans during the 1940-41 bombing blitz of the second world war to destroy the vital port of Liverpool, ${ }^{17}$ the Dispensary miraculously escaped any serious damage.

\section{Penicillin era}

Although, initially, sulphanomides were found to be very effective in the treatment of gonorrhoea, their value had decreased considerably by 1944 as a result of the emergence of resistant strains. However, penicillin, which had by then become available, soon revolutionized the treatment of syphilis as well as gonorrhoea. The number of new cases, especially of 
syphilis, began to decline. The decline was much more significant in the total number of attendances because prolonged and repeated courses of arsenicals and bismuth and weeks of irrigation treatment for gonorrhoea were no longer necessary.

The advent of penicillin (and later, other antibiotics, such as tetracycline) also encouraged self treatment at sea (a practice which has continued ever since), making the proper assessment of the cases on arrival at the shore clinic more difficult. The inevitable widespread use of antibiotics led to the emergence of strains of Neisseria gonorrhoeae resistant to penicillin as well as other antibiotics. This was certainly one of the reasons for the persistently high numbers of cases of gonorrhoea, (table 1), especially if one takes into account the fact that, in the earlier years and up to 1950 , cases of nongonococcal urethritis would have been included as gonorrhoea.

In 1976, when there was an epidemic due to the penicillinase-producing $N$ gonorrhoeae in Liverpool, the Seamen's Dispensary had its fair share. The epidemic was, however, brought under control and has been well documented. ${ }^{18}$

Work practices and work load (1950-1980)

As a result of the National Health Service Act 1946, the control of Venereal Disease Services was transferred from the Liverpool City Council to the Regional Hospital Board and the Board of Governors of the United Liverpool Hospitals.

After the death of Dr Ross, in 1954, Dr Ernest Earlam Prebble (1904-1990) succeeded as Consultant-in-charge. He had been a Brigadier in the Army and he held office until his retirement ten years later, at the age of sixty. Dr Prebble was a man of few words, not difficult to please, courteous, business-like, not anxious to disturb the Establishment. But he did do battle to obtain (full-time) what was then known as a contact tracer. In this he did not succeed but one was appointed soon after his departure. So his efforts, undoubtedly, assisted in that.

Nevertheless, contact-tracing and follow-up of defaulters continued to be pursued vigorously by close co-operation with the Welfare Officers and the female clinics in the city. (In Liverpool, this very essential aspect of STD control has traditionally been given the importance it deserves. And that, most certainly, must be the principal reason why we have been able to keep under control the incidence of syphilis, gonorrhoea, chlamydia, and now also HIV infection).

Until 1955 all the non-medical staffing of the clinic consisted of male orderlies. Then two State Enrolled Nurses (male) were engaged, but a Charge Nurse (also male) was not appointed until 1957, and a records clerk only in 1963. Before that the nurses did all the clerical duties in what had by then become one of the busiest clinics in the country fully engaged in the training of medical students and male nurses. Such was Dr Prebble's outlook, that no female was ever permitted to cross the threshold during clinic hours, not even a typist. Letters were written by hand or taken to be typed elsewhere. 1963 also saw the appointment of a Senior Registrar.

In 1964, resignations from nursing staff had caused difficulties. Poor layout was thought to be an undoubted factor in the staff dissatisfaction. Consequently, the building underwent certain structural alterations and was completely redecorated. These improvements were much appreciated by staff and patients alike. ${ }^{19}$

One of the annual reports refers to the provision of an excellent laboratory. ${ }^{20}$ This was a room with a cupboard, a wallpoint and running water. Before that a microscope was kept under a glass dome, in the doctor's office, and methylene-blue staining was done over a sink where everyone washed their hands.

There were other quaint customs too. Every Wednesday morning, all the glass slides used during the preceding week were boiled in a solution of lysol. The odour can be more easily imagined than described. The slides were then re-used. And the needles used for venepuncture and intramuscular injection were sterilised by boiling in water, and occasionally, sharpened on a grindstone.

The above practice of reusing needles and slides was discontinued in 1965. However, glass syringes, sterilised by steam pressure in an autoclave, wrapped in small hand-made linen bags remained in use until about 1970 .

By 1960, the irrigation cubicles had been dismantled except one which was retained for occasional use but mainly on account of historical interest. Nongonococcal urethritis had also begun to be recognised as a major problem.

In 1965, more vigorous criteria were reported to have been adopted for the diagnosis of both gonorrhoea and syphilis, making it difficult to compare with the previous years' figures. ${ }^{19}$

Routine plating of specimens of urethral discharge was only introduced in 1965. Before that cultures were chiefly sought for specimens from homosexuals and married men who denied extra-marital relationships.

\section{Undergraduate and postgraduate teaching and} research

Liverpool, being a great port, had an abundance of clinical material. The Seamen's Dispensary served a useful function in the training of medical students, postgraduate students and male nurses. Liverpool was one of the few centres providing postgraduate training in venereology in the 1930s. The University of Liverpool continued to grant the Venereal Disease Officer's Certificate up to 1967. Much of the clinical instruction for this was given at the Seamen's Dispensary.

In 1967 the University of Liverpool became the first university in Europe to offer a full time course and to award a Diploma in Venereology. ${ }^{21}$ The Seamen's Dispensary has continued to be one of the two main centres for the instruction in the specialty up to its closure in December 1991.

The abundant clinical material in the Seamen's Dispensary has been a source of very 
fruitful and original research over the years resulting in a number of publications in reputable scientific journals.

1980-1990

The attendances at the Seamen's Dispensary had remained stable between 1950 and 1970 . From 1980, however, the numbers, with the exçeption of those in 1985, had been declining (table 1). This may have been due to a number of factors.

Firstly, the population of Liverpool has been declining since 1975 when it was 548,800 . In 1989 it was 465,910 . Innumerable families have been rehoused in the surrounding areas and GUM clinics have been opened in the neighbouring towns.

Secondly, Liverpool was no longer a major seaport (table 2). The number of ships calling at the port of Liverpool had plummeted from 10,164 in 1960 to only 3,013 in 1985 (personal communication, Mersey Docks and Harbour Co). The liners carrying the passengers ceased using the port in 1966 . This was probably one of the main reasons for the drop in attendances at the Seamen's Dispensary. Whereas over $80 \%$ of those attending the Dispensary in the 1920 s and 1930s were seamen, the proportion was $10 \%$ in 1980 and less than $6 \%$ in 1990 . The plausibility of this explanation was strengthened by the fact that, compared with the Seamen's Dispensary, the only other major clinic in the city, the Royal Liverpool University Hospital which did not traditionally attract seamen, has been seeing twice the number of patients per session during the last four years.

Unattractive premises perhaps may also be a factor. From the more scientific point of view, however, the Seamen's Dispensary had outlived its usefulness. It did not stand up to the modern concepts of a GUM clinic for the 1990 s, recently defined in an authoritative report. ${ }^{22}$ The serious shortcomings included lack of privacy, lack of adequate space to examine patients and to teach students. In addition, it suffered the inconveniences associated with any health facility remote from a District Hospital.

Consequently, the Seamen's Dispensary had to close. The only problem was that the existing GUM clinic premises at the Royal Liverpool University Hospital (RLUH) opened in 1979, although purpose built, had in the recent years been felt to be seriously inadequate. An opportunity arose, as a result of the reorganisation of the RLUH (after acquiring Trust status) in 1991, of the availability of new purpose built

Table 2 Number of ships and their tonnage passing through the port of Liverpool

\begin{tabular}{lrl}
\hline Year & Number of Ships & Tonnage \\
\hline 1930 & 13,454 & $16,184,515$ \\
1940 & 10,333 & $14,305,715$ \\
1950 & 9,189 & $15,372,207$ \\
1960 & 10,164 & $19,838,134$ \\
1970 & 7,803 & $20,970,000$ \\
1980 & 4,540 & $26,372,000$ \\
1985 & 3,013 & $19,612,000$ \\
\hline
\end{tabular}

and much larger premises within the hospital, enough to absorb also the workload of the Seamen's Dispensary. That certainly was the ideal answer.

Space does not allow mention of all the staff who worked at the Seamen's Dispensary, but their commitment was total. They strove to maintain high standards at all times. The only turnover was due to normal retirement. The services of the present staff have been transferred to the new large department which is only a mile away. Nevertheless, having worked for so many years in a place which had almost become an institution, a feeling of loss was understandable.

Most importantly, several of our patients, who were loyally attracted to the Seamen's Dispensary, will experience similar loss. They can be assured of a better service of a high quality which remains our foremost objective.

We thank Mr W I Murrary (the City Solicitor), Mr Neville Carick (the Director of Libraries and Arts), Dr R W Moye (Consultant Communicable Disease Control), and Mr R Burgess (Department of Environmental Health) for providing access to the Venereal Disease Special Sub-Committee Minute and the Annual Reports on the health of the City of Liverpool, respectively from 1921 to 1938 , and from 1916 to 1945 , as well as for permission to reproduce figs 2 and 3 . We thank also the Mersey Docks and Harbour Company for information on shipping and Churchill Livingstone for permission to Te are reproduce fig 4. We are grateful to Drs Elisabeth Rees an Frederick Lancely, the retired con
reading through the manuscript.

1 Hyde FE. Liverpool and the Mersey, Newton Abbot, David and Charles, 1971.

2 Lane T. Liverpool, Gateway of Empire, London, Lawrence and Wishart, 1987, 22

3 Huggil S. Sailortown, London, Routledge \& Kegan Paul, 1967, 108 .

4 Bickerton HR. Mackenna RMB. A Medical History of Liverpool from the Earliest days to the Year 1920. London, John Murray, 10, 17

5 Final Report of the Commissioners' Royal Commission on Venereal Diseases. London, HMSO, 1916.

6 Waugh MA. History of clinical developments in sexuall transmitted diseases. In: Holmes KK, Mardh PA Sparling PF, Weisner PJ, Cates W, Lemon SM, Stamm WE, eds. Sexually Transmitted Diseases, 2nd ed., New York, McGraw-Hill, 1990, 3-15.

7 Liverpool Public Health Department. Report on the Health of the City of Liverpool During the Year 1916, 3, 44.

8 Liverpool Public Health Department. Report on the Health of the City of Liverpool During the Year 1917, 27.

9 Liverpool Public Health Department. Report on the Health of the City of Liverpool During the Year 1919, 76, 77, 82 .

10 The Merchant Shipping Act, 1906, Section 34, London, HMSO

11 Venereal Diseases Special Sub-Committee, Hospitals and Port Health 352 MIN/HOS/15/1, 15 February, 1921

12 Liverpool Public Health Department. Report on the Health of the City of Liverpool During the Year 1923 with Observations up to June 30th, 1924, 132.

13 Obituary, Andrew Oliver Ferguson Ross, Br J Venereal Dis 1954;30:171.

14 Liverpool Public Health Department. Report on the Health of the City of Liverpool During the Year 1926, 142

15 Liverpool Public Health Department. Report on the Health of the City of Liverpool During the Year 1928, 136, 137.

16 Ross AO. The problem of the treatment of venereal disease in the mercantile marine. BrJVenereal Dis 1929;5:210-9.

17 Whitworth R. Merseyside at war. Liverpool, Scouse Press, 1988 .

18 Arya OP, Rees E, Percival A, Alergant CD, Annels EH, Turner GC. Epidemiology and treatment of gonorrhoea caused by penicillinase-producing strains in Liverpool. $B$ JVenereal Dis 1978;54:28-35.

19 South Liverpool Hospital Management Committee. Annual Report, 1 April 1965 to 31 March, 1966, 81.

20 South Liverpool Hospital Management Committee. Annua Report, 1 April 1955 to 31 March, 1956, 68

21 Alergant CD. A Diploma in Venereology. Br J Venereal Dis 1970;46:162-3.

22 Department of Health. Report of the working group to examine workloads in genitourinary medicine clinics. London. Department of Health, 1988. 